\title{
Costumbres y tradiciones en torno al embarazo y al parto en el México virreinal
}

\author{
Martha Eugenia Rodríguez \\ Departamento de Historia y Filosofía de la Medicina \\ Facultad de Medicina \\ Universidad Nacional Autónoma de México
}

\begin{abstract}
Se analizan los cuidados y prácticas que se llevaban a cabo durante el embarazo y el parto en la Nueva España. Prácticas que podían ser de carácter supersticioso, religioso o profano y que era importante valerse de ellas debido a que el embarazo se veía como un proceso natural y fisiológico y, a su vez, el momento del parto era temido porque se corría el riesgo de perder la vida.

Otros apartados que se comentan son el de la operación cesárea, cuya práctica se introdujo en la Nueva España en el siglo XVIII en medio de mucha resistencia por parte de los profesionales de la salud; el aborto, que fue fuertemente sancionado no sólo por parte de la Iglesia, sino también del Real Tribunal del Protomedicato y, finalmente, la profesión de la partera, quien no obstante que no contaba con una formación académica, resolvía un problema de salud a todas las clases sociales.
\end{abstract}

\section{Introducción}

Cuando una mujer está embarazada participa de una serie de creencias populares y lleva a cabo una diversidad de cuidados y prácticas con el propósito de tener un periodo de gestación saludable y lograr un parto fácil, puesto que el acto de parir suele estar rodeado de temor debido a que se le ve como un momento en el que se puede perder la vida. Las creencias y costumbres que se asocian con el embarazo y el parto se han acumulado a través del tiempo debido, entre muchas otras razones, como asienta Foster, ${ }^{1}$ a que la dilación del embarazo en la mujer recién casada puede crearle una incómoda posición dentro de la familia y su círculo social, según la cultura de que se trate. Podría llegar a parecer que no está cumpliendo con una de sus responsabilidades dentro del matrimonio. Otro hecho muy común es que si en un tiempo razonable la mujer casada no queda embarazada, es víctima de críticas y lástimas, de aquí la necesidad de no pasar por alto las creencias populares. Una vez que se ha dado a luz, la mujer adquiere un nuevo estatus en la sociedad, donde pasa de mujer a madre.

1 Foster, George: "Folklore y costumbres del embarazo, nacimiento e infancia", La antropología médica en España, Michael Kenny y Jesús M. de Miguel (Editores), Barcelona, 1980, pág. 250. 
Estas creencias y prácticas pueden ser de carácter supersticioso, religioso o profano, libre de fuerzas del orden sagrado. De manera particular analizaré las costumbres y tradiciones sobre el embarazo y el parto en la Nueva España, en las cuales se da una interrelación de ideas europeas e indígenas; cabe señalar que muchas de ellas tienen una larga tradición, llegando hasta nuestros días. Asimismo estudiaré otros puntos enmarcados dentro de la obstetricia, como son la operación cesárea, el aborto y la formación de la partera. La información aquí presentada está basada fundamentalmente en fuentes primarias, escritas en su mayoría en los siglos XVIII y XIX, provenientes de diversos archivos: el Archivo Histórico de la Facultad de Medicina de la Universidad Nacional Autónoma de México, el Archivo General de la Nación de México y el Wellcome Institute for the History of Medicine de Londres.

En el periodo virreinal, el embarazo y el parto se veían por parte de la población española y mestiza como un proceso absolutamente natural y fisiológico, a diferencia de las creencias prehispánicas donde los dioses tenían una fuerte intervención debido a que los indígenas no tenían una idea precisa de los mecanismos de la concepción. Sin embargo, entre la población novohispana se observan ideas y actividades de naturaleza mística, que son necesario llevar a cabo en virtud de que existe el riesgo de que la madre o la criatura pierdan la vida.

La presencia de ideas de naturaleza mística se explica tomando en cuenta que la medicina no se puede estudiar como una entidad aislada de otras formas de cultura de una sociedad, sino que existe una interacción entre ellas. Así pues, para comprender la historia de la medicina es necesario tomar en consideración otros factores de orden social, educativo, religioso, etcétera, y en la época de estudio, la religión cátolica fue un importante factor cultural que influyó en la evolución de la medicina. Por ejemplo, desde el siglo XVI la fundación de hospitales se debió a la Corona española, a donaciones particulares y a las órdenes religiosas; asimismo, la función del hospital no sólo consistía en dar asistencia a los enfermos, sino también en brindar hospedería y practicar la caridad cristiana, además de que su construcción debía hacerse próxima a una iglesia. Por otra parte, aparecieron, al lado de los libros de temática médica propiamente dicha, una serie de publicaciones médico-religiosas, entre ellas las oraciones y las novenas, que tenían como fin la prevención y curación de las enfermedades; es decir, fue común la influencia religiosa en el ámbito médico.

En el periodo novohispano, el ejercicio de la obstetricia estuvo en manos de las parteras o comadronas, aunque no de manera oficial; los 
médicos no se ocupaban de tan denigrante profesión. Fue hasta el siglo XVIII cuando las parteras fueron reconocidas por parte de las autoridades encargadas de vigilar el ejercicio de la medicina; antes de este siglo solamente eran toleradas. De ellas, Ignacio Segura, médico de la Corte, se expresaba diciendo: "El oficio de la partera es utilísimo para la salud de las almas y de los cuerpos, y aún para la conservación del género humano, por ello son llamadas mujeres sabias y comadres, como si fueran segundas madres de los infantes". ${ }^{2}$ Eran mujeres prácticas que a sí mismas se denominaban parteras y, por lo regular, de edad avanzada. La idea que entonces prevalecía era que las parteras debían ser buenas cristianas y confiadas más en los auxilios de Dios que en los de su arte, “...pues devotamente implorados, los concede su Divina Providencia suficientes para salir del mayor aprieto". ${ }^{3}$ La partera tenía la tarea de cuidar durante todo el embarazo a su paciente. Para el ejercicio de su profesión contaba con una ayudante conocida como tenedora, quien preparaba todo lo necesario para que se pudiera llevar a efecto el parto.

\section{El embarazo}

En todas las épocas, las creencias y prácticas que giran alrededor del embarazo y del parto están influidas por factores culturales, con un arraigamiento tal, que se ha demostrado por la antropología médica que es más fácil lograr cambios en la práctica sanitaria que en las creencias y actitudes no sólo sobre la gestación y el momento del parto, sino también sobre la etiología y el control de la enfermedad. ${ }^{4}$ Las costumbres y prácticas aquí presentadas tienen un carácter preventivo, cuya finalidad consiste en que el embarazo se desarrolle sin contratiempos y que el alumbramiento sea exitoso.

Entre las costumbres llevadas a cabo para lograr un buen embarazo cabe citar la recomendación, de origen europeo, consistente en que ni por temor ni por vergüenza las mujeres embarazadas dejaran de pedir aquellas

2 Segura, Ignacio: Avisos saludables a las parteras para el cumplimiento de su obligación. Sacados de la Embriología Sacra del Sr. Dr. Francisco Manuel Cangiamila y puestos al castellano por el Dr. D. I. Segura, médico de la Corte, México, 1775, pág. 1.

3 Medina, Antonio: Cartilla nueva útil y necesaria para instruirse las matronas que vulgarmente se llaman Comadres, en el oficio de partear, mandada a hacer por el Real Tribunal del ProtoMedicato, México, 1806, pág. 4.

4 Miguel, Jesús de: "Introducción al campo de la antropología médica", La antropología médica en España, Barcelona, 1980, pág. 33. 
cosas que se les antojaran, pues de no cumplir estos deseos, las consecuencias podrían ser graves, como provocar el aborto y, por tanto, la muerte de la criatura. Asimismo, sobre el antojo de la mujer embarazada se creía, como en la época prehispánica, que era una manifestación de las necesidades del niño a través de su madre y, de no cumplirlo, el producto sufriría.

Existieron creencias que no poseen ningún fundamento terapéutico, es decir, de carácter supersticioso, como fue el hacer uso de objetos dotados de un contenido simbólico. Por ejemplo, para ayudar a la continuidad del embarazo se recurría a la piedra imán, llevándola consigo la embarazada. En la Metrópoli se decía que había que llevarla debajo de la axila.

Respecto al sexo del feto, los conquistadores también introdujeron la idea de que era señal de que se había concebido un varón los siguientes signos: "color del rostro manchado y apagado, movimientos del feto, cuando mas tarde, pasados los tres primeros meses: sumo aborrecimiento al congreso y calor grande que suele sentirle en el lado del bazo". Cuando se había concebido una niña, los signos eran diferentes: “...suavidad de los efectos del preñado, por las pocas manchas de la cara y porque los meteoritos del vientre no cesan hasta los cuatro meses". 5

Un remedio para combatir los sustos y miedos de las mujeres gestantes, que puede tener un cierto fundamento, era el consumir una bebida calificada como antiepiléptica compuesta, entre otros productos, de láudano, preparación que contiene vino blanco, azafrán y otras sustancias, así como canela y jarabe de rosa. De ello la embarazada debía tomar una cucharadita de tiempo en tiempo. ${ }^{6}$

Creencia popular de origen europeo fue que los sietemesinos podían vivir tan bien como los niños nacidos a los nueve meses de gestación. Sobre ello los pitagóricos pensaban que el número 7 era perfecto, por ser impar, de aquí que los niños nacidos en ese mes tuvieran altas probabilidades de vivir. Durante la Edad Media, el número 7 también se consideró de buena suerte, dado que representaba el día de Dios. Como el número ocho es par, se le consideraba imperfecto, por lo que el niño tendría pocas posibilidades de vivir, menos que los sietemesinos, y en caso de que viviera, sería de

5 Venegas, Juan Manuel: Compendio de la medicina ó medicina práctica en que se declara laconicamente lo mas util de ella, que el Autor tiene observado en estas Regiones de Nueva España, para casi todas las enfermedades que acometen al cuerpo humano: dispuesto en forma alfabética, México, 1788, pág. 4.

6 Ibídem, pág. 5. 
manera enfermiza. ${ }^{7}$ Esta creencia carece de fundamento en virtud de que el feto de ocho meses está en mejores condiciones que el de siete.

Tanto durante el embarazo como en el momento del parto, la mujer embarazada se valió de diversos rituales. Éstos constituyen un elemento relevante en la manera de cómo determinados grupos sociales enfrentan los momentos en que existen peligros o amenazas. Los rituales tienen importantes dimensiones simbólicas tanto sociales como psicológicas, cuyo lenguaje, expresado a través de diversas maneras, movimientos, palabras, canciones, música, etcétera, se entiende bien en un contexto cultural específico y sólo por aquellos que conocen su significado. ${ }^{8}$ Cada ritual es un cúmulo de símbolos y actos que revelan algo acerca de los valores de la sociedad: el alumbramiento es un momento único, de una importancia innegable.

En la sociedad novohispana fueron abundantes las estampas, las pinturas, esculturas, reliquias y oraciones. Por su parte, la partera también tenía sus recursos, que colocaba en el abdomen o en el cuello de la parturienta, como escapularios, rosarios y medallas. Entre dichas prácticas cabe citar las Palabras de la Virgen, jaculatoria impresa en una oblea o papel que comían las embarazadas, aún a la hora del parto. Dicha jaculatoria también se encontraba impresa en una faja con listones de colores que se colocaba sobre el vientre de la parturienta, y cuyo texto decía: "En tu Concepción ó Virgen María fuiste inmaculada: Ruega por nosotros al Padre cuyo hijo diste á luz. ${ }^{9}$ El fajamiento se practicaba para evitar que "suba la criatura" o para que "no se agarre en las entrañas del pecho".

Respecto a los santos se argumentaba en una novena de 1818 que todos “...son abogados nuestros en el cielo; todos ruegan allí y piden por nosotros: de todos debemos o podemos esperar el remedio de nuestras necesidades, pero de ninguno con más confianza que de aquellos que sobresalieron en este mundo en la caridad y misericordia con sus prógimos". ${ }^{10}$ Así, los santos protectores de las embarazadas y del parto más venerados fueron San Vicente Ferrer, San Félix de Cantalicio, San Carlos

7 Castillo Ojugas, A: "Obstetricia popular (notas sobre folklore obstétrico)", Archivos Iberoamericanos de Historia de la Medicina, t. III, Madrid, 1951, pág. 595.

8 Helman, C.: Culture, Health and Illness. An Introduction for Health Professionals, London, 1990, págs. 192-193.

9 León, Nicolás: La obstetricia en México. Notas bibliográficas, Etnicas, Históricas, Documentarias y Críticas de los orígenes históricos hasta el año 1910, México, 1910, pág. 145.

10 Valdés, Juan F.: Novena consagrada al culto del Glorioso San Antonio del Aguila del Sagrado Orden del Padre y Doctor San Agustín: conocido con el epíteto por médico de los pobres, México, 1818, págs. 1-2. 
Borromeo, San Ignacio de Loyola, San Taraco Mártir, Santo Domingo de Silos y San Ramón Nonato. De igual manera, fue común encontrar en el periodo estudiado imágenes de la Virgen en sus diferentes advocaciones, a quienes invocaban las parturientas en el momento de dar a luz, como Nuestra Señora de la Salud en Pátzcuaro y Nuestra Señora de la Caridad en San Cristóbal de las Casas. En la Nueva España sucedió, lógicamente, como en la metrópoli, que los rezos de las mujeres embarazadas se dirigieron fundamentalmente a los santos, en menor proporción a la Virgen y mucho menos a Dios. ${ }^{11}$

Entre los santos abogados de las mujeres embarazadas está San Ramón Nonato, de la Orden de Nuestra Señora de la Merced. Debe su sobrenombre a la circunstancia de haber sido extraído vivo del seno de su madre, después de haber muerto ésta. Nació en Cataluña el año de 1220 y murió 40 años después. En 1657 el Papa Alejandro VII le incluyó en el martirologio. Desde entonces ha sido muy grande la devoción que se le ha profesado en Cataluña, la cual ha sido acrecentada por la Iglesia, fundamentalmente a partir de 1681, cuando fue extendida a todo el mundo la celebración de su fiesta en la fecha que hoy en día conocemos, el 31 de agosto. Tanto en vida como después de su muerte, se le han atribuido a San Ramón Nonato numerosos milagros en diversas epidemias, pero su más singular protección se ha experimentado en los partos, en memoria de la forma como llegó a este mundo.

La devoción a San Ramón Nonato pasó a nuestro territorio con los conquistadores. La Iglesia recomendaba que en todos los partos y fundamentalmente en los más dificultosos se le rezara y se pidiera a Dios por el buen suceso de ellos y que no se usaran oraciones prohibidas y sospechosas, siendo lo más acertado abstenerse de todas las que no estuvieran aprobadas por dicha institución. Su novenario, especial para las embarazadas, se publicó en la Nueva España en 1780 y se reimprimió en 1848. En él se decía que para tener un feliz parto se debía seguir la siguiente recomendación: durante los nueve meses de embarazo, una vez por mes, debían ir a visitar su capilla en el convento de la Virgen de la Merced, haciendo las siguientes diligencias: empezar a ejecutar la novena desde el primer mes, empezando un domingo, día en que murió el Santo Cardenal. Las mujeres que visitaran la capilla deberían ir confesadas y comulgadas, y allí rezar 10

11 Limón, A. y Castellote, E.: "La medicina popular en torno al embarazo y el parto a principios de siglo", La antropología médica en España, Barcelona, 1980, pág. 234. 
padres nuestros, 10 aves marías y 10 veces "Gloria Patri”, para en seguida decir la siguiente oración:

¡O San Ramón No Nacido, prodigioso! a ti vengo, movida de la grande benignidad con que tratas á tus devotos. Acepta, Santo mio, estos pasos, que de muy buena gana he dado, desde mi casa á esta capilla, en memoria de los que tú diste, tan meritorios, que alcanzaron de Dios el que te haya constituido patron especial de las preñadas. Aquí está, Sto. mío, una de ellas, que se pone humilde debajo de tu protección y amparo: suplicándote, que así como se conservó siempre invicta tu paciente en todos aquellos ocho meses, en que fuiste singularísimamente martirizado con el candado, y otras penas que padeciste dentro de la tenebrosa mazmorra, y al noveno mes saliste libre de todas aquellas prisiones; así Santo y abogado mio, te pido humildemente me alcances de mi Dios y Señor el que esta criatura que está encerrada en la obscura cárcel de mis entrañas, se conserve en vida y salud por ocho meses, y en el noveno salga libre á la luz de este mundo: haciendo tú, Santo mio, que asi como el día que salió tu alma de tu santo cuerpo, fué día Domingo, que es día de gozo; así lo sea el que yo la dé á luz, con todas aquellas circunstancias que tú sabes que mas convienen á mayor gloria de Dios, y tuya, y salvación de mi alma. Amén. ${ }^{12}$

La oración anterior servía durante los ocho meses del embarazo; sin embargo, para el noveno mes, en lugar de rezar una sola vez al mes, como se había estado haciendo, era necesario hacer la novena entera por espacio de nueve días. Asimismo, para la Virgen de las Mercedes se rezaba la siguiente oración:

¡O piadosísima Virgen de las Mercedes! Suplícote por las entrañas dulcísimas de tu piedad, oigas á la afligida que te llama; y por el que sin dolor pariste, y por los meritos de tu siervo San Ramón, cuyo nacimiento fué milagroso, me favorezcas en este parto: yo te ofrezco ser humilde esclava tuya para mejor servir á tu unigénito Hijo Cristo redentor nuestro. Amén. ${ }^{13}$

La tradición de acudir a San Ramón Nonato no correspondió únicamente a siglos pasados, aún hoy en día se le reza. En la ciudad de México su imagen se encuentra a un costado del altar del templo de Belem de los Mercedarios o más comúnmente conocido como Capilla de las Merceditas.

Entre las oraciones eficaces para ayudar a tener un buen embarazo y un parto fácil, ahora de carácter supersticioso, a pesar de la represión que existía por parte del Tribunal de la Inquisición, estaba la oración a la Santa Piedra Imán, pero trayendo consigo un fragmento del mineral.

12 Novena del Glorioso S. Ramón No Nacido. Cardenal de la Santa Iglesia Romana, del Nacional orden de nuestra Señora de la Merced redención de cautivos, abogado de las mujeres preñadas y protector de los dolores de cabeza, México, 1848, págs. 27-28.

13 Ibídem, pág. 30. 


\section{El parto}

El trabajo de parto se llevaba a cabo en el domicilio de la parturienta. Con anticipación se llamaba a la partera, en quien desde el inicio de la gestación se había depositado una total confianza; sin embargo, no era suficiente con saber que se trataba de una persona experimentada; además de esto, los familiares de la parturienta, y ella misma, hacían su lucha para que el momento del alumbramiento fuera exitoso, valiéndose tanto de medios físicos como de preceptos mágicos y religiosos, puesto que el miedo de la madre surge mucho antes de las primeras contracciones previas al parto. El Tribunal del Protomedicato afirmaba que era difícil encontrar una partera que no tuviera nexos con la magia.

Costumbre popular para el momento del parto fue emplear una posición arrodillada, como en la época prehispánica, colocándose la comadrona delante de la parturienta y la tenedora a su espalda, siendo tarea de ambas sacar a la paciente del incómodo momento en que se encontraba. Sin embargo, conforme transcurre el periodo virreinal la mujer adoptó otras posiciones para el acto de parir: una fue sentada en una silla especial, que con anticipación se mandaba al domicilio de la parturiente, como se usaba en Europa, y ya entrado el siglo XIX también se puso en práctica la posición de litotomía, siendo esta última la de menor uso.

En el trabajo de parto, la partera y la tenedora iniciaban su labor despojando a la parturienta de la ropa innecesaria; ésta se colocaba en la posición adecuada, ya fuera en una silla o de rodillas, y entre la partera y la tenedora presionaban el abdomen de la paciente, de manera que a cada contracción uterina le seguía una fuerte presión por parte de la comadrona.

Helman ${ }^{14}$ asevera que en casi todas las culturas se excluye al hombre de la escena del parto, donde su posición se limita a la de un espectador ansioso por el nacimiento de su hijo. En las fuentes consultadas no hemos encontrado referencia alguna al papel que juega el esposo a la hora del alumbramiento en el territorio novohispano. Parecería que se trata de un asunto femenino y a nivel casero, donde la atención médica quedaba en manos de las madres, abuelas y, por supuesto, de las comadronas; hecho explicable, en parte, porque en la Nueva España no existió esa tendencia de que habla Helman, que consiste en medicalizar un fenómeno biológico nor-

14 Helman, C.: Culture, Health... pág. 155. 
mal, como es el embarazo, para volverlo un problema médico y convertir a la mujer embarazada en "una paciente pasiva y dependiente". ${ }^{15}$

En la literatura de la época se dieron ciertas recomendaciones para el trabajo de parto que reflejan bien el pensar de aquel entonces, donde dicho trabajo tenía que llevarse a cabo con mucha discreción, como se muestra en la siguiente cita. A la hora del parto,

"la enferma estará cubierta según la estación, estando desnuda lo menos posible; los ojos del operador deben estar en la punta de sus dedos, él debe sentir sin ver nada, ó sentir como si todo lo viese; asi debe estar dotado de un tacto fino y delicado, tratando de resguardar su epidermis tocando ó frotandolos los menos posible contra cuerpos duros, poniéndola á cubierto del contacto del aire frío, lo que debe conducirle á usar guantes en todo tiempo para tener la piel de las manos suave y sensible". ${ }^{16}$

Habíamos comentado que la parturienta daba a luz en su domicilio; sin embargo, para las mujeres españolas y criollas que no podían realizar el trabajo de parto en sus casas debido a que ocultaban su embarazo, o bien, porque no deseaban al recién nacido, se creó el 4 de noviembre de 1774 un Departamento de Partos Reservados, ubicado en el Hospicio de Pobres de la ciudad de México, quedando a cargo de un eclesiástico, aunque los partos los atendía la comadrona. Si el recién nacido no era deseado por la madre, podía pasar a la Casa Real de Expósitos. ${ }^{17}$ Era mucha la discreción que se guardaba en dicho establecimiento. El ingreso de la mujer se hacía varios días antes del parto; llegaba con la cara cubierta y, si así lo deseaba, podía permanecer con el rostro cubierto durante toda su estancia, o bien, únicamente en el momento del parto. El Departamento de Partos Ocultos tenía como objetivo, en la medida de lo posible, evitar el infanticidio. Sin embargo, su creación obedeció también a otros fines, siendo éstos de orden moral, social y religioso: amparaba a las madres solteras o abandonadas, cuidaba el decoro de las familias, el honor de muchos matrimonios y la tranquilidad de la sociedad, de acuerdo a la mentalidad que entonces imperaba.

Sobre los embarazos ocultos e ilícitos las parteras estaban obligadas, bajo pena de pecado mortal, a guardar un total silencio. No era lícito matar a la criatura, aunque fuera "demasiado fea o monstruosa", y si contaban con tiempo suficiente, debían llamar al cura para que determinara si se había de

15 Ibídem, pág. 146.

16 Maygrier, Jacques Pierre: Nuevo método para operar los partos, Méjico, 1821, pág. 18.

17 Ordenanzas para el Gobierno del Hospicio de Pobres de la Ciudad de México en sus cuatro Departamentos, México, 1806, pág. 33. 
bautizar al "monstruo". En los partos ilegítimos tocaba a la partera amonestar a las madres y a sus allegados, sin hacer daño a las criaturas. Las parteras también estaban obligadas a asistir gratuitamente a las pobres y ayudarlas con todo el esmero, por lo que Dios les pagaría la caridad, pero de lo contrario, vengaría este agravio.

Tarea de la partera era salvar la vida física y espiritual de la criatura; es decir, si la partera veía en peligro la vida del recién nacido, aún dentro del vientre materno, o bien, si temía que sus padres lo mataran, ésta tenía la obligación de bautizarlo, actuando de diferente manera según el caso: si la criatura sacaba la cabeza, la partera debía bautizarla en ella, con la condición de que no debía ser nuevamente bautizada cuando naciera. Si la partera descubría alguna otra parte y no la cabeza, tenía que bautizarla allí bajo advertencia "si eres capaz" y cuando la criatura naciera completamente, debía bautizarla en la cabeza diciendo: "si no estás bautizado y si eres capaz, yo te bautizo en el nombre del Padre, del Hijo y del Espíritu Santo". De igual forma, si existía el riesgo de que la criatura muriera antes de llevarla a la iglesia, también era la partera quien tenía que bautizarla. ${ }^{18}$ Las señales para conocer dicho riesgo eran, entre otras, que la criatura naciera sin llorar, si daba muestras de sofocamiento, si estaba débil, moreteada o si nacía antes de los siete meses.

Como medida preventiva para evitar la mortalidad infantil, en 1797 el marqués de Branciforte, virrey de Nueva España, daba a conocer una real orden donde encargaba al Tribunal del Protomedicato que vigilara a las comadres y cirujanos que atendieran los partos, a fin de que aplicaran a los recién nacidos en el corte del cordón umbilical el Bálsamo de Copayba, conocido también como aceite de palo o aceite canimar, en vez de "otros ingredientes ó inútiles ó dañosos" como eran el sebo y la sal. El Bálsamo de Copayba se utilizaba para prevenir "el mal de siete días", una de las principales enfermedades que causaba la despoblación, en ese entonces muy común en Cuba. ${ }^{19}$

Algunas de las creencias populares respecto al parto eran, por una parte, que las mujeres que dan a luz con frecuencia se llegan a esterilizar en algún momento. Asimismo fue común el uso de la llamada Rosa de Jericó. Al empezar el parto, la rosa se colocaba dentro de un recipiente con agua, de manera que cuando la planta hubiera extendido sus ramas, el parto se llevaría a cabo.

18 Segura: Avisos saludables..., pág. 8.

19 Branciforte, marqués de: Real orden sobre el descubrimiento de un específico preservativo del mal de siete días, Orizaba, 1797, pág. 1. 
En el periodo que estudiamos eran varias las causas a las que se atribuían las dificultades en el parto: a movimientos graves del cuerpo, contusiones o compresiones fuertes del vientre; pasiones violentas, antojos y pesadumbres; a fiebres, pujos, diarreas, flujos de sangre; estrechez en la vulva; criatura atravesada, débil o muerta y debilidad de la parturienta o temor. De aquí que los recursos empleados para facilitar el mal parto fueran diversos. Comprendían remedios que pueden tener un cierto fundamento, ritos, prácticas tradicionales y supersticiones.

Entre las supersticiones que dominaban en la Nueva España estaba el uso de la piedra cuadrada. De ella se decía: "La piedra cándar, o piedra quadrada o quebrada tiene la hechura de un dado, y el color del azero, es pesada...traenla de los confines de la Tartaria los Bonzos, los cuales dicen que tiene muchas virtudes, y por esta razón la agujeran, y la traen á el pescuezo colgada". Y entre las virtudes de la piedra estaba el remediar los dolores de cabeza, las punzadas, los cólicos, aliviar el asma, contra la melancolía y para facilitar el parto. Según decía el doctor Marcos Salgado:

"Sirve esta piedra, atada al muslo izquierdo, para facilitar el parto, estando la muger en términos de parir, porque la experiencia tiene mostrado, que aplicada en este estado, obra lo que se desea: en caso que esta diligencia no baste, refregarán la dicha piedra medio quarto de hora con una onza de azeyte de ajonjolí caliente, y lo darán á beber á la Muger, y luego parirá, y echará las pares, y la criatura, sin riesgo ni peligro de la madre, advirtiendo, que luego que la muger para, ó echare la criatura, y las pares, se quita luego la dicha piedra, porque si la dexaren atada mucho tiempo, saldrá la madre fuera de su lugar y las entrañas todas; como yo vi y observé en una muger...”. ${ }^{20}$

Otro remedio para solucionar los partos dificultosos, también sin fundamento alguno, era el uso del Palo de Fresno, "puesto sobre el vientre que parirá ó si nó, excremento de caballo desleido en vino, y bien colado, y beber medio quartillo, que aunque la criatura esté muerta, la arrojará con facilidad". ${ }^{21}$

Para lograr un parto exitoso fueron comunes las velas llamadas de "Nuestra Señora de la Consolación", de "Nuestra Señora de la Luz" y las velas llamadas de "San Ramón Nonato", así como la medalla de este último santo. A la hora del parto la vela debía encenderse y la parturienta tenía que colocarse la medalla al cuello. De igual manera se ponían al cuello escapularios y amuletos.

20 Salgado, Marcos José: Virtudes de la piedra cuadrada, México, 1730, pág. 1.

21 Michael, M.D.: Botica general de remedios experimentados que a beneficio del público se reimprime por su original en Cádiz, Puebla, 1797, pág. 15. 
Como señala Foster, ${ }^{22}$ las creencias y costumbres en torno al embarazo y al parto parecen caer en la categoría de los elementos transmitidos informalmente, donde sorprende que las formas españolas predominen entre los círculos mestizos y los grupos indios aculturados, debido a que, por tratarse de un sector de "cultura femenina", podría esperarse que las mujeres nativas, como esposas o concubinas de los conquistadores, continuaran la práctica de sus propias costumbres y las perpetuaran dentro de esa población mestiza.

\section{La operación cesárea}

La operación cesárea, consistente en extraer el feto a través de una incisión uterina por vía abdominal, se empezó a llevar a cabo en la Nueva España hasta el siglo XVIII, aunque siempre realizada en mujeres fallecidas. Este intento desesperado de salvar al feto en caso de la muerte de la madre tiene sus raíces en las culturas de la antigüedad (egipcios, hebreos, etcétera $\left.{ }^{23}\right)$. Su práctica obedecía a que era el único medio para evitar que se sepultaran con las madres difuntas las criaturas vivas, y fueran socorridas para lograr la vida eterna. Es decir, las cesáreas tenían por objeto asegurar la vida espiritual de los niños por medio del bautismo. El Ritual Romano, elaborado bajo la dirección de Pablo V, de 1605 a 1621, puntualizaba que si se extraía el feto muerto, es decir, si no había posibilidad de administrarle el sacramento del bautismo, no debía inhumarse en lugar santo. Demerson ${ }^{24}$ comenta que es lógico pensar que esos mandamientos se siguieran en todos los países católicos, aunque resulta difícil precisar en qué medida. Para salvar la vida espiritual del feto, el virrey de Nueva España, don Antonio María de Bucareli y Ursúa, expidió una circular el 21 de noviembre de 1772 donde apoyaba la práctica de dicha operación. En el documento se advertía que cualquier persona que rehusara la práctica de la operación cesárea o diera a conocer la noticia demasiado tarde, se le sancionaría con una multa de 500 pesos, ya fuera el facultativo, el padre, el marido o parientes de la difunta..$^{25}$

22 Foster: Folklore y costumbres..., págs. 261-262.

23 Demerson, Paula de: "La cesárea post mortem en la España de la Ilustración", Asclepio, Archivo Iberoamericano de historia de la medicina y antropología médica, t. XXVIII, Madrid, 1976, pág. 185.

24 Ibídem, pág. 186.

25 Bucareli: Circular para la pronta aplicación de la operación cesárea, México, 1772, pág. 1. 
La operación cesárea, practicada en mujeres vivas, se realizó bajo múltiples controversias desde el siglo XVI en algunos países europeos; sin embargo, en España no tuvo buena acogida, de aquí que en la Nueva España no se pensara siquiera en ello, ${ }^{26}$ sólo en la cesárea post mortem, considerada como un deber de conciencia por parte de los que rodean a la mujer embarazada, debido al fin que se alcanzaba: la salvación espiritual del producto.

A su vez, el Arzobispo de México, Alonso Núñez de Haro y Peralta, al hablar de que una de sus obligaciones era conseguir la salvación eterna, ordenó que, cuando se hiciera la operación cesárea en mujeres fallecidas, se bautizara al recién nacido. Y con base en una Real Pragmática publicada en España el año de 1749 por el rey Carlos III, mandaba también en 1772 que se castigase a la persona que se opusiera a ejecutar la citada operación, pues condenaban al feto, según se creía, a ser enterrado vivo. Asimismo establecía que en virtud de que no siempre había cirujano o persona que pudiera ejecutar dicha operación, “...es nuestra voluntad, que todos los curas y vicarios compren y tengan en su casa un librito pequeño que ha dado a la prensa el R.P. Joseph Manuel Rodríguez...en el cual explica el modo con que comoda y fácilmente se hace la operación, á fin de que los curas y vicarios lo hagan por sí mismos quando no haya persona secular que pueda hacerla...." ${ }^{27}$

Con la filosofía ilustrada el intercambio de ideas y publicaciones se incrementó de manera notable, lo que hizo posible que en la Nueva España se conocieran los avances europeos. De aquí el entusiasmo que se manifestó por la práctica de la operación cesárea post mortem, operación que contaba con el apoyo del Real Tribunal del Protomedicato. Testimonio de ello son las publicaciones que aparecieron en la Nueva España, como la mencionada obra de Joseph Manuel Rodríguez La caridad del sacerdote para con los niños encerrados en el vientre de sus madres difuntas y documentos de la utilidad y necesidad de su práctica, impresa en 1773 y traducida del italiano al español de acuerdo al libro Embriología Sacra, ó del oficio de los Sacerdotes, Médicos y Superiores acerca de la salud eterna de los Niños encerrados en el útero del canónigo italiano Francisco Manuel Cangiamila, que había sido publicado en Milán en 1745 y donde habla sobre la práctica de la operación cesárea. En la Nueva España la impresión del libro de Rodríguez se autorizó el 16 de septiembre de 1772, pues "cons-

26 Demerson: La cesárea... pág. 189.

27 Núñez, Alonso: Operación llamada parto cesáreo, México, 1772, pág. 1. 
ta no tener cosa que se oponga á nuestra Santa Fé, buenas costumbres...". ${ }^{28}$ El libro “...tiene un objeto tan piádoso, qual es la salud eterna de los párvulos, que ciertamente él mismo (Rodríguez) es el mas justo aprobante, y eloquente Panegyrista, haciendola digna no solo de la mayor recomendación, sino de que sea promovida su práctica". ${ }^{29}$

De igual manera, sobre el tema se imprimió en la Nueva España el año de 1775 la obra del Dr. Ignacio Segura, médico de la Corte, Avisos saludables a las parteras para el cumplimiento de su obligación, extraídos también de la obra del Dr. Cangiamila.

Dado el acuerdo referente de que cuando no hubiera partera ni médico, la operación cesárea la haría el sacerdote, Joseph Manuel Rodríguez daba a conocer que era algo fácil de ejecutar: “...siendo cosa incomparablemente mayor el hacer el oficio de partera con una viva, que el solo abrir el costado de la muerta... mas para no verse los párrocos reducidos a estos peligros requiere la razón que procuren con tiempo tener muchos en sus parroquias, que sepan practicar la operación cesárea parteras, sangradores ó barberos, y en especial algún cirujano verdaderamente caritativo, y que esté siempre pronto á la caza de aquellos parvulitos". ${ }^{30}$ En caso de que el cirujano se negara a efectuar la cesárea por no poderse cubrir sus honorarios, el cura debía pagar los gastos de las mujeres de escasos recursos, pues ante todo estaba la salvación eterna de los niños. El libro de Cangiamila, que Rodríguez tradujo al español, insiste en practicar la cesárea post mortem sin hacer caso de las opiniones de médicos y parteras cuando aseguran que el feto ya ha fallecido; sin embargo, el Ritual Romano otorgaba autoridad a los médicos para decidir si el feto tenía vida o si ya estaba muerto. ${ }^{31}$

El arzobispo de México sugería varios pasos a quien hiciera la operación cesárea. Verificar primero que la embarazada estuviera muerta y, de ser así, extraer la criatura del vientre materno para posteriormente administrarle el sacramento del bautismo, por lo que exhortaba a los sacerdotes seculares y regulares a que contribuyeran con sus particulares persuasiones a desterrar el horror con que comúnmente era vista dicha operación, tan necesaria para salvar la vida corporal y espiritual de los niños que perdían

28 Rodríguez, Juan María: La caridad del sacerdote para con los niños encerrados en el vientre de sus madres difuntas y documentos de la utilidad y necesidad de su práctica, México, 1773, pág. 45.

29 Parecer del P. Dr. y Mtro. D. Juan Gregorio de Campos. Presbytero de la Real Congregación del Oratorio de N.P.S. Felipe Neri de México, Real Congregación de S. Felipe Neri, México, pág. 2, en Rodríguez, J.M. La caridad...

30 Rodríguez: La caridad... pág. 18.

31 Demerson: La cesárea... pág. 201. 
a sus madres antes de nacer. De igual manera, los sacerdotes tenían que estar prevenidos con una navaja para poder ejecutar la operación.

Al principiar el siglo XIX la Corona española continuaba insistiendo en la práctica de la operación cesárea. En abril de 1804 el rey de España daba la orden de que en el Real Colegio de Cirugía se practicara dicha operación en mujeres muertas, y en caso de que no hubiera facultativo, tocaría al párroco decidir quién la practicaría. Estos últimos no debían consentir que se diera sepultura a mujer alguna que hubiera fallecido embarazada, sin que les constara que se hubiera efectuado la operación. En la Nueva España la noticia anterior se dio a conocer cuatro meses más tarde. En el documento se explicaba cómo hacer la operación, empezando por verificar que la madre estuviera muerta, y aunque ya hubieran pasado muchas horas de su fallecimiento, se debía practicar la cesárea, y aunque el embarazo fuera de muy poco tiempo, se tenía que hacer lo mismo, a fin de bautizar al recién nacido. ${ }^{32}$ La Real Orden de 1804 nos hace pensar que fue a partir de esta fecha cuando los profesionales de sexo masculino, es decir, los cirujanos o médicos, se empezaron a ocupar de la ejecución de la operación cesárea, y por ende, del ejercicio de la obstetricia, pues los asistentes al Real Colegio de Cirugía eran los cirujanos y médicos y no las parteras que, como ya se mencionó, se formaban de manera empírica. A partir de la publicación de la obra de Cangiamila, la cesárea post mortem se generalizó en países como Francia y España, y por tanto, en la Nueva España, donde fue fomentada por la Iglesia y el Gobierno, aunque no sabemos con qué frecuencia se practicó.

Según las fuentes consultadas, la primera operación cesárea en mujer viva hecha en México se realizó en julio de 1850 por el doctor Miguel Jiménez en el Hospital de San Pablo. ${ }^{33}$

\section{El aborto}

El aborto es la pérdida espontánea o provocada del producto de la concepción antes de que sea viable. En el periodo estudiado muchos abortos y partos dificultosos eran causados, según las creencias de entonces, por las constituciones astrales, por el aire o por encontrarse en lugares muy frescos.

32 Real Orden sobre la práctica de la operación cesárea en mujeres que han fallecido, Copia del original expedido en Aranjuez el 13 de abril de 1804, México, 1804, pág. 2.

33 Icaza, A. y Luna, C.: "Historia de la cesárea en México", Revista de la Facultad de Medicina, t. VIII, México, 1996, pág. 503. 
En la sociedad novohispana el aborto intencionado era fuertemente sancionado. La partera o cualquier otra persona que aconsejara o cooperara de algún modo al aborto, pecaba mortalmente, aunque la criatura ya hubiera fallecido. La muerte de la criatura se podía pronosticar tomando en cuenta diversos síntomas: “...las molas carnosas que en la preñez se hubieran arrojado, el color del rostro roxo, mudado repentinamente en aplomado, la inflamación de las partes naturales, y convulsión, que sobrevienen á el excito; y las enfermedades agudas que son causas del mal parto, y traen alguna erupción de sangre, como la disentería, pulmonía, dolor de costado, etc.". ${ }^{34}$

Obligación de la partera era alejar a la mujer embarazada de tan perversa intención, haciéndole saber las penas que ello traería; si por sí misma no podía hacer algo, debía avisar secretamente al cura para que interviniera y lo evitara. Entre las lecturas que se recomendaban a las parteras, estaba el libro ya citado de Cangiamila, a través del cual se combatía la práctica del aborto, que no se justificaba en ningún caso, ni por vengüenza, temor o miseria. Creencia generalizada fue la de que si después del aborto venía una epilepsia, indicaba que el aborto había sido provocado intencionalmente. Asimismo las parteras tenían la obligación de advertir a las mujeres embarazadas que el abuso de las relaciones sexuales durante el embarazo podría provocar un aborto. Entre los signos que antecedían a éste, cabe citar los dolores en el vientre, acompañados de algún frío u horripilación, repentino flujo de sangre o de agua y debilitamiento del cuerpo.

Se recomendaba a las parteras que si la criatura abortada estaba viva y bien formada, se debía bautizar sin condición alguna; si estaba viva pero mal formada, el bautizo se haría, como ya se ha mencionado, bajo la condición "si eres capaz", en virtud de que existía la duda en cuanto a saber si tenía alma racional, pues no se podía establecer el momento en que ésta se adquiría, aunque se llegó a afirmar por parte de algunos médicos que la animación se daba en el momento de la concepción.

Los métodos para evitar el aborto han sido de diversa índole; en el orden de lo supersticioso cabe mencionar el uso de las piedras preciosas, como se hacía en la antigüedad; en lo religioso, la costumbre de llevar escapularios o cordones de hábito alrededor del vientre y, de carácter profano, ahora sí con algún fundamento terapéutico, el uso de la herbolaria, como se hacía en la Nueva España.

34 Venegas: Compendio de... págs. 3-4. 


\section{La profesión de partera}

Tanto en la época prehispánica como en el periodo virreinal el ejercicio de la obstetricia estuvo prácticamente en manos de especialistas de sexo femenino, es decir, de las parteras, no obstante que quienes estaban legalmente autorizados para el ejercicio de la profesión eran los cirujanos romancistas, denominados así porque no habían cursado estudio alguno. Francisco Flores $^{35}$ sostiene que la educación obstétrica empezó en la Nueva España con la fundación del Real Colegio de Cirugía en 1768, dirigiéndose a los cirujanos romancistas. En opinión de Nicolás León, no se impartía dicha enseñanza. Por nuestra parte, nos inclinamos a decir que se comenzó a enseñar en el Real Colegio de Cirugía a partir de 1804, de acuerdo con la real ordenanza que hemos citado. Pero no obstante que el cirujano romancista era la persona autorizada por el Real Tribunal del Protomedicato para ejercer la obstetricia, en la práctica eran las parteras quienes ejercían dicha profesión. Creemos que fue hasta principios del siglo XIX cuando el cirujano empezó a intervenir en esta tarea. De acuerdo a Nicolás León no hay noticia de que alguno de los célebres médicos que ejercieron la medicina en los siglos XVI y XVII se hubiera dedicado al ejercicio de la obstetricia, afirmando que los cirujanos mismos parece que desdeñaron el ocuparse de ello. Respecto al siglo XIX habla de dos cirujanos hábiles en el arte de la obstetricia: Francisco Montes de Oca y José Miguel Muñoz.

$\mathrm{Al}$ igual que los barberos, boticarios, algebistas, hernistas y otros profesionales, las parteras tampoco estaban obligadas a hacer estudios. Su preparación era de manera empírica, al lado de una comadrona bien habilitada. Asimismo, muchos de los conocimientos de las parteras venían de su propia experiencia, de los embarazos que hubieran tenido. Sólo la práctica de la especialidad era necesaria para que las parteras fuesen reconocidas por la sociedad en general, y de alguna manera también por el Real Tribunal del Protomedicato, organismo encargado de vigilar el ejercicio de la medicina. Esta institución autorizaba la actividad de la partera, pero con ciertas restricciones. En los dos primeros siglos del periodo virreinal no hubo disposición alguna que mejorara la enseñanza de la obstetricia o que estableciera exámenes especiales, a fin de dar garantía a las pacientes de la aptitud de los que ejercían la profesión. Las parteras no tenían establecimiento en donde

35 Flores, Francisco: Historia de la medicina en México desde la época de los indios hasta la presente, (edición facsimilar), t. 2, México, 1982, pág. 470. 
aprender: su oficio era hereditario; el ejercicio de la obstetricia lo practicaban las mujeres que se consideraban experimentadas en el arte de los partos.

A partir de la segunda mitad del siglo XVIII la alta mortalidad materno-infantil es denunciada por mucha gente e inquieta a los países europeos, de aquí que sus gobernantes fijaran como objetivo prioritario la formación de la partera. En Francia se generalizó la preocupación de que la mortalidad, debida a la ignorancia de las comadronas, podría causar el despoblamiento de la nación. ${ }^{36}$ Estas ideas ocasionaron que se multiplicara la literatura obstétrica, inclusive en España, y por ende, en Nueva España, de aquí que para mediados de la centuria ilustrada la fuente de adiestramiento de las parteras no fuera sólo el ejercicio diario, sino también los libros que llegaban de la Península.

Para 1750, cuando la Corona española se preocupó por el ejercicio de las comadronas, el Rey Fernando VI mandó que el Tribunal del Protomedicato de la Nueva España aplicara exámenes teóricos y prácticos a las parteras y les expidiera títulos, y en caso de que no fueran aprobadas, quedarían privadas con graves penas de ejercer su oficio. Para poder aspirar a un título, era necesario reunir varios requisitos: probar su limpieza de sangre y que habían tenido un ejercicio de tres años hecho con cirujano y partera aprobada, lo que demuestra que de alguna manera las parteras sí eran reconocidas por las autoridades, debido a que cumplían una función importante y resolvían un problema social y de atención médica; por tanto, tenían que ser toleradas, pues su práctica permeó a todas las clases sociales.

Los médicos estaban en desacuerdo con dejar el ejercicio de la obstetricia en manos de las parteras, dados los abusos que cometían y la superstición que envolvía su práctica, pero tampoco lo retomaban, puesto que el oficio de los partos es, como señala Gélis ${ }^{37}$ para la Francia del siglo XVIII, y que bien se puede aplicar a otras regiones, el más disgustoso, vil y degradante de la cirugía. Agrega que la sangre vertida en el parto genera repulsión, pues no es la misma sangre que ven los cirujanos en una operación. La sangre del parto se consideró impura, como la de la menstruación, ocasionando entonces que el desprecio recayera sobre la persona que aceptaba dar su ayuda en el momento del alumbramiento; sin embargo y pese a todo, la partera cumplía con importantes funciones, salvar no sólo la vida corporal de sus pacientes, sino también la espiritual.

36 Gélis, J.: "Sages-femmes et accoucheurs: l'obstétrique populaire aux XVII et XVIII siecles”, Annales Economies, Sociétés, Civilisations, n. . 5, París, 1977, pág. 938.

37 Ibídem, pág. 932. 
Sobre la ignorancia y desprecio de las parteras, el médico José Ignacio Bartolache expresaba en 1772 por medio del periódico el Mercurio Volante que:

"A las Damas seglares quisiera ponderar cuan mal hacen en abandonarse en sus preñados y partos a la indiscreción de las Parteras, sus Comadres, cuya maniobra no tiene nada que ver con las licencias y facultades que esa gente se toma de ordinario no sin grave daño de las pacientes. He notado en esto infinitos abusos de mucha consecuencia. Las personas que repugnarían un medicamento prescrito por un médico docto toman los brevajes más absurdos y desatinados como sea de orden y mano de las comadres. ¿Qué diremos de los sacudimientos para poner la criatura en su lugar? Porque no hablo ahora del misterioso baño que toman las paridas, maestreando las ceremonias una viejecilla ignorante, y ridículamente supersticiosa. Esto es cosa de risa. Hablemos claro, señoras: mientras no aprendieren estas mujeres la arte de partear, escrita y perfeccionada hoy por hombres muy hábiles, es disparate fiarse de las Comadres para otra cosa, que para recibir y bañar la criatura y mudar ropa limpia a la parida". ${ }^{38}$

Cabe hacer notar que cuando Bartolache publicaba su periódico, a pesar de que las parteras ya se examinaban, lo hacían sin tener estudio alguno. Respecto al misterioso baño a que se refiere Bartolache, es el temazcal o baño de vapor, utilizado fundamentalmente en el postparto. Data de la época prehispánica y aún hoy en día sigue utilizándose en ciertos grupos indígenas. A través de las fuentes se ha destacado su calidad terapéutica, higiénica y ritual; purificaba por medio del fuego y del agua, curaba diversas enfermedades y servía para que "sanaren" las recién paridas. A pesar de que Bartolache se expresaba con desdén sobre el baño, fue ampliamente reconocido por las autoridades gubernamentales. Para abrir un temazcal era necesario contar con la autorización de la Junta de Policía y con una licencia expedida por el virrey. ${ }^{39}$

Durante muchos siglos los médicos y cirujanos no se interesaron por la obstetricia, pues se consideró una actividad femenina; sin embargo, la partera asume un papel sumiso ante el cirujano, mientras que éste se muestra soberbio frente a la comadrona. Por su parte, la mujer embarazada frecuentemente veía al cirujano con repugnancia y lo consideraba como un verdugo, depositando toda su confianza en la comadrona, sin importar la

38 Bartolache, José Ignacio: “Avisos acerca del mal histérico que llaman latido" del miércoles 25 de noviembre de 1772, Mercurio Volante (1772-1773), México, 1979, pág. 55.

39 Archivo Histórico del ExAyuntamiento de la Ciudad de México (AHCM). Policía. Baños y lavaderos, v. 3621 , t. 1 , exp. 2 , 1792, fs. 8-9. 
formación que tuviera. En el siglo XVIII fue tema de discusión la ignorancia de las parteras; hubo una acusación unánime contra ellas ${ }^{40}$ no sólo en países europeos como Francia y España, sino también en la Nueva España. El lamentable estado de la obstetricia, la inexistencia de una formación sólida para las comadronas, los nacimientos secretos y la superstición que prevalecía en el trabajo que realizaban, condujo a que los profesores de medicina de la Real y Pontificia Universidad de México pusieran de manifiesto la necesidad de reformar la regulación de las parteras. Por su parte, el Tribunal del Protomedicato asentaba que entre los rudos artesanos no había tanta idiotez como entre las parteras. ${ }^{41}$

A partir de la disposición dada por Fernando VI, se empezaron a dar instrucciones a las parteras. El 26 de mayo de 1793 el virrey Revillagigedo mandó al Real Tribunal del Protomedicato que previniese a los cirujanos, médicos y parteras que era su obligación asistir al enfermo oportunamente a la hora que se les llamara, de lo contrario se les aplicarían severas sanciones. Por otra parte, también a partir de la orden dada por Fernando VI, el Tribunal del Protomedicato de la Metrópoli encargó al doctor Antonio Medina que escribiera una Cartilla, a manera de preguntas y respuestas, para instruir a las parteras, la cual fue publicada en Madrid el año de 1750. Su impresión en la Nueva España se realizó en 1806. Dicha obra constó de cuatro secciones: 1) definiciones y cualidades físicas y morales de una comadre, 2) de la anatomía, 3) del estado de la preñez y 4) del parto. La enseñanza del arte de parir debía fundarse en el conocimiento anatómico de las partes de la generación de la mujer. Se hacía énfasis en que la matrona debía saber

"la constitución de la pelvis huesosa, y de las partes situadas en el ínfimo vientre. La verdadera idea y conocimiento de estos huesos, de su figura, tamaño y articulación, no la pueden conseguir las matrones por la sola explicación y noticia que se les dé en los libros, y así es necesario que á presencia de esqueleto, y de un Maestro Anatómico lo pretendan, por ser el medio mas breve y eficaz para conseguirlo suficientemente". ${ }^{42}$

Para el ejercicio de la obstetricia, el Real Tribunal del Protomedicato ordenó ciertas limitantes a las parteras: no debían recetar medicamentos, no podían hacer operación de ninguna clase y en casos laboriosos tenía que

40 Gélis: Sages-femmes... pág. 928.

41 Lanning, John Tate: The Royal Protomedicato. The Regulation of the Medical Professions in the Spanish Empire, Durham, 1985, pág. 323.

42 Medina: Cartilla nueva... págs. 10-11. 
acudir al médico o al cirujano. Por su parte, Medina también insistía en su Cartilla que en los partos difíciles las parteras debían acudir al cirujano.

Para la instrucción de las comadronas fueron varios los libros publicados en el periodo estudiado. No obstante que ya han sido citados a lo largo de este trabajo, cabe reunir aquí nuevamente los títulos: el Padre Joseph Manuel Rodríguez tradujo del italiano al español la obra de Francisco Cangiamila bajo el título de La caridad del sacerdote para con los niños encerrados en el vientre de sus madres difuntas, el año de 1773. Por su parte, Ignacio Segura, médico de la Corte, publicó el libro Avisos saludables a las parteras para el cumplimiento de su obligación en 1775; igualmente, con base en la obra de Francisco Cangiamila, en 1806 Antonio Medina, también médico de la Corte y examinador del Real Tribunal del Protomedicato, publicó la obra Cartilla nueva útil y necesaria para instruirse las matronas que vulgarmente se llaman comadres, en el oficio de partear. La publicación de estas obras en la Nueva España fue de gran trascendencia dado que son evidencias de los primeros intentos para dar una educación a las parteras, que si bien debieron haber sido muy hábiles en ciertos aspectos empíricos como en el cálculo del mes de la preñez o en el de la posición del feto, les era necesario adquirir muchos conocimientos más, referentes, por ejemplo, a los principios fundamentales de la higiene o al reconocimiento de los casos difíciles, donde debían llamar al médico.

\section{Comentarios finales}

Hemos señalado que en la sociedad novohispana el embarazo fue visto como un proceso natural, de aquí que existiera el riesgo de que éste se interrumpiera o de perder la vida durante el parto o de que éste se dificultara, por lo que fue necesario valerse de ciertos recursos para evitar riesgos. Las costumbres que existieron en torno al embarazo y al parto fueron muy particulares a la ideología de entonces, resultando del sincretismo de las culturas indígena y europea. Muchas de las prácticas llevadas a cabo tanto en el ámbito de lo supersticioso, religioso o profano sobreviven hoy en día, lo que refleja su continuidad histórica; indudablemente en todo ello la sugestión juega un papel muy importante.

Fue hasta finales del Siglo de las Luces cuando en la Nueva España la práctica de la obstetricia pasó por una serie de reformas, con base en las innovaciones que en aquel entonces se estaban dando en la Metrópoli, 
como la práctica de la operación cesárea, la publicación de libros especializados en el tema que se comenta, la instrucción de la obstetricia en el Real Colegio de Cirugía y el reconocimiento oficial de las parteras por parte del Real Tribunal del Protomedicato, hechos que sin duda alguna contribuyeron a enriquecer la especialidad.

Por otra parte, es necesario destacar la figura de la partera, cuyo ejercicio de la profesión oscilaba entre lo legal y lo ilegal, dependiendo de los recursos que utilizara. No contaba con una formación académica, puesto que no había donde hacerla, pero se le toleró por parte del Tribunal del Protomedicato debido a que en términos prácticos resolvía un problema de salud, que hasta muy avanzado el virreinato fue desdeñado por los médicos y cirujanos; durante muchos años éstos se limitaron a teorizar en manuales y centraron su atención en otras especialidades de la medicina. En aquel entonces la partera ocupó un lugar trascendente en el ejercicio de la obstetricia. Sin embargo, conforme avanzó el tiempo, la implantación de los estudios sistemáticos, los avances de la cirugía y de la ciencia irían despojando a la partera de la obstetricia, en favor de los cirujanos, con quienes se empezaron a hacer innovaciones y a poner en práctica el uso de técnicas nuevas. En las grandes ciudades, el equipo moderno de las clínicas despojó totalmente a las parteras de su trabajo, aunque hoy en día siguen aplicando su saber, pero restringido a niveles socioeconómicos bajos y a zonas rurales. 